\title{
Effects of feeding a pigmented or non-pigmented diet to Arctic charr, Salvelinus alpinus, on flesh color and sexual maturity
}

\author{
Mary A. McNiven ${ }^{1^{*}}$, Gavin F. Richardson ${ }^{1,2}$, Claude S. Pelletier $^{3}$ \\ ${ }^{1}$ Department of Health Management, Atlantic Veterinary College, University of Prince Edward Island, Charlottetown, Canada; \\ *Corresponding Author: mcniven@upei.ca \\ ${ }^{2}$ Present Address: 13 Advana Avenue, Charlottetown, Canada \\ ${ }^{3}$ Coastal Zones Research Institute, Shippagan, Canada
}

Received 18 August 2012; revised 23 September 2012; accepted 30 September 2012

\begin{abstract}
The objective of this study was to evaluate the effects of feeding pigmented feed (50 ppm astaxanthin) to diploid or triploid Arctic charr, Salvelinus alpinus, on growth rate, color of fillets, and the variability of color within fillets. Arctic charr with an average weight of $419.9 \mathrm{~g} \pm$ $83.3 \mathrm{~g}$, including both diploid $(n=72)$ and triploid $(n=72)$ fish, were allotted to each treatment: 0,3 or 6 months of pigmented feed before slaughter. Color assessment was made using a portable reflected light colorimeter in the CIE $1976 L^{*} a^{*} b^{*}$ color system mode. Feeding a pigmented diet to Arctic charr delayed sexual maturity in male Arctic charr and to a certain extent in females, but also slightly reduced the rate of growth. With increasing time on the pigmented diet, color parameters of the flesh increased as well as the variability in color. Triploid fish had more intense color assessments for each dietary treatment than the diploid fish.
\end{abstract}

Keywords: Arctic charr; Pigment; Color; Maturation

\section{INTRODUCTION}

The Arctic charr, Salvelinus alpinus, is a salmonid species well-suited for commercial production in northerly conditions. The development of the Arctic charr industry in Eastern Canada has been hindered in part by quality concerns of the fillets. Color and appearance are important attributes for consumer acceptability [1], with pricing based on the intensity of the red hue [2] in some salmonids. Variable fillet pigmentation has frequently been reported for Arctic charr [1], and although increasing the dietary pigment concentration may improve flesh pigmentation, this will also increase the cost of supplementation above $10 \%$ - $15 \%$ of feed costs [3].

In addition, early sexual maturation may be one of the greatest constraints to commercial success of the industry [4]. Sexual maturation of the fish results in reduced growth due to increased gonadal growth, poorer flesh quality and pigmentation, and decreased marketability [5]. The use of triploidy induction to produce sterile populations of fish is the most effective way to reduce the negative effects of sexual maturation in Arctic charr [6].

This study was designed to evaluate the effects of feeding pigmented feed (50 ppm astaxanthin) to diploid or triploid Arctic charr for different lengths of time on growth rate, color of fillets and the variability of color within fillets.

\section{MATERIALS \& METHODS}

Arctic charr with an average weight of $419.9 \mathrm{~g} \pm 83.3$ $\mathrm{g}$, including both diploid (non-sexed) $(\mathrm{n}=72)$ and triploid ( $n=72)$, were allotted to each treatment: 0 months of pigmented feed, three months of pigmented feed or six months of pigmented feed before slaughter. The feeds used were Ewos Vita (0 ppm astaxanthin) and Ewos Pacific (50 ppm astaxanthin). The feeding rates were 1.2\% of biomass per day for Months 0 to 3, and $1.0 \%$ for Months 4 to 6 according to the manufacturer's recommendations. Information about the background of the fish and triploidy induction was reported by [4]. All fish were branded and fin-clipped for identification.

The fish were housed in two $4 \mathrm{~m}^{3}$ tanks recirculated at $95 \%$ with injected oxygen and town water passed through carbon filters to extract chlorine and under a natural photoperiod with a light intensity of about 40 lux throughout the experimental period. Because of the constraints of available tank space, P0 and P3 fish were housed in the same $4 \mathrm{~m}^{3}$ tank while the P6 fish were housed in a similar tank at $12^{\circ} \mathrm{C}$. After three months, the 
P3 fish were removed from the tank containing fish fed the non-pigmented feed and were housed in the tank containing fish fed the pigmented diet. After 6 months of feeding, all fish were weighed and slaughtered at the same time. The gonads were dissected out and weighed, and the fillets were held at $4^{\circ} \mathrm{C}$ until color assessment was made within $24 \mathrm{~h}$.

Color assessment on the fillets and skin was made using a portable reflected light colorimeter (CR200, Minolta Co. Ltd. Osaka, Japan). The instrument was calibrated to a standard white plate and recordings were made in the CIE $1976 \mathrm{~L}^{*} \mathrm{a}^{*} \mathrm{~b}^{*}$ color system mode [7].

Results were analyzed using a two-way analysis of variance with dietary treatment and sex as the main effects and interaction [8]. To calculate the degree of variability in color in the flesh, the standard deviations of five measurements of color assessment were determined and two-way analysis of variance with dietary treatment and sex as the main effects and interaction was used.

\section{RESULTS}

The mean body weights ( \pm SEM) according to sex and dietary treatment are shown in Table 1. The interaction between dietary treatment and sex was significant for both parameters. All male fish, and female or triploid fish on the non-pigmented diet, had significantly higher body weights at slaughter compared to female or triploid fish on pigmented feed.

The weight of the gonads and the gonadosomatic index (GSI) are shown in Table 1. The interaction between dietary treatment and sex was significant for both parameters. In general, male and female fish had higher gonad weights and GSI on the non-pigmented feed compared to fish on any length of time on the pigmented feed except for the female fish which had similar gonad weights and GSI for 0 and 3 months on the pigmented feed. At any length of time on the pigmented diet, female fish had a higher GSI than the males or the triploid fish.

Color parameters for the Arctic charr flesh are shown in Table 2. There was a significant interaction between dietary treatment and sex for all three parameters. For each sex, the length of time on a pigmented diet had a marked effect on the lightness, redness and yellowness of the flesh. For the lightness parameter $\left(\mathrm{L}^{*}\right)$, female fish

Table 1. Body and gonad weight, and gonadosomatic index of Arctic charr fed a pigmented diet for 0, 3 or 6 mo. and slaughtered after 6 mo. The number of fish per treatment (0, 3 or 6 mo.) and sex were: Female, 15, 10, 11; Male, 9, 14, 13; Triploid, 24, 24, 24, respectively.

\begin{tabular}{|c|c|c|c|c|c|c|c|c|c|c|c|c|}
\hline & & \multicolumn{2}{|c|}{ Weight, g } & \multicolumn{5}{|c|}{ Gonad weight, g } & \multicolumn{4}{|c|}{ Gonadosomatic index } \\
\hline \multicolumn{4}{|c|}{ Months on pigmented feed } & \multicolumn{5}{|c|}{ Months on pigmented feed } & \multicolumn{4}{|c|}{ Months on pigmented feed } \\
\hline & 0 & 3 & 6 & SEM & 0 & 3 & 6 & SEM & 0 & 3 & 6 & SEM \\
\hline Female & $993.5 \mathrm{z}$ & $870.0 \mathrm{yx}$ & $914.1 \mathrm{yx}$ & 60.0 & $101.7 \mathrm{z}$ & $101.1 \mathrm{z}$ & $77.2 \mathrm{y}$ & 6.47 & $10.5 \mathrm{zy}$ & $11.7 \mathrm{z}$ & $8.9 \mathrm{y}$ & 0.67 \\
\hline Male & $1088.6 \mathrm{z}$ & $1016.1 \mathrm{zy}$ & $999.2 \mathrm{z}$ & 60.0 & $46.4 x$ & $12.6 \mathrm{w}$ & $14.5 \mathrm{w}$ & 6.49 & $4.41 \mathrm{x}$ & $1.45 \mathrm{w}$ & $1.43 \mathrm{w}$ & 0.67 \\
\hline Triploid & $1051.0 \mathrm{z}$ & $923.5 \mathrm{yx}$ & $853.5 \mathrm{x}$ & 41.8 & $8.03 \mathrm{w}$ & $3.04 \mathrm{w}$ & $2.75 \mathrm{w}$ & 4.53 & $0.80 \mathrm{w}$ & $0.32 \mathrm{w}$ & $0.34 \mathrm{w}$ & 0.47 \\
\hline
\end{tabular}

zyxw means within a parameter with different letters are different $(P<0.001)$.

Table 2. Color parameters of flesh and skin from Arctic char fed a pigmented diet for 0, 3, or 6 months.

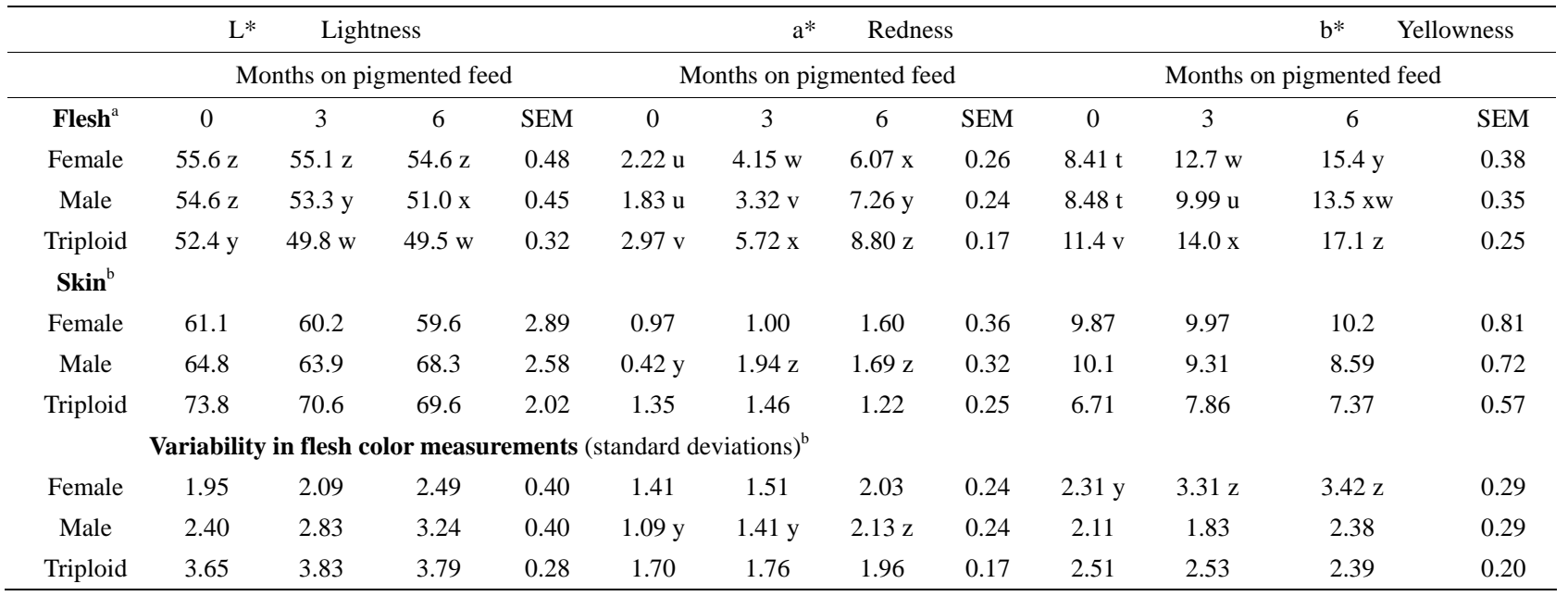

a. Significant interaction between sex and dietary treatment. Means within Flesh and Color parameter with different letters are significantly different $(P<$ 0.0001); b. Means within Skin and Variability and Color parameter with different letters are significantly different $(P<0.01)$. 
were not affected by length of time on the pigmented diet while male fish and triploids had a decreasing amount of lightness with increasing length of time on the pigmented diet. For the redness parameter $\left(a^{*}\right)$, all sexes of fish had an increase in $a^{*}$ with increasing time on the pigmented diet, although the effect was most pronounced for the triploid fish. For the yellowness parameter $\left(b^{*}\right)$, again all sexes of fish had an increase in $b^{*}$ with increasing time on the pigmented diet and the effect was more pronounced for the triploid fish. In fact, the $b^{*}$ level for the triploids on the non-pigmented diet was also significantly higher than for the males or females.

Variability in flesh pigmentation was estimated by the standard deviation of five measurements of color assessment for each fillet (Table 2). Overall, there was a significant increase in the variability of redness with six months of dietary pigmentation $(2.04 \pm 0.123)$ compared with three months $(1.56 \pm 0.124)$ or zero months of dietary pigmentation $(1.40 \pm 0.126)$ primarily due to a significant increase in the variability of the $a^{*}$ of the male fish. For the lightness parameter, triploid flesh had the highest degree of variability, and the female fish had the lowest. The female fish had the highest degree of variability in the yellowness parameter and had a significantly higher variability of $b^{*}$ for either pigmented feed treatment than female fish on the non-pigmented feed.

For skin color parameters (Table 2), the only treatment difference within sex was for the male fish and a* which was significantly higher for fish on either pigmented feed compared to fish on the non-pigmented feed.

\section{DISCUSSION}

The pinkish-red color of salmonid flesh is due to the accumulation of carotenoids from the diet into the muscle. During growth, dietary carotenoids accumulate in the muscle, and then are released for several uses during the reproductive process. During sexual maturation, feeding behavior is reduced or stopped, and the resultant negative nutrient balance results in white muscle breakdown to support the development of gonads and eggs. During this muscle degradation, there is an accompanying increase in free radical production, and this additional oxidative stress load is large enough to have caused the evolution of compensatory processes in iteroparous fish [9]. Astaxanthin is a very powerful antioxidant and its release from muscle during sexual maturation may play a role in maintaining tissue integrity [9].

In addition, in females, carotenoids are thought to function during fertilization by stimulating and attracting spermatozoa to the eggs [10], and to be beneficial to the viability of the fertilized eggs during incubation and the growth and development of the fry [11]. In male fish, carotenoids are redistributed to the skin from the muscle during sexual maturation and contribute to the increased skin pigmentation needed to signal fighting ability to other males [12], and to act as an attractant to females [13]. Pigmentation of the flesh is also used as an attractant for consumers, as redness of fillets contributes to the overall enjoyment of cooked salmonid fish [14] and may have a signaling value as an indicator of product quality [15].

In the present study, exposure to dietary carotenoids delayed sexual maturation in the female and male Arctic charr (Table 1). This is contrary to the report of [16] who found that sexual maturation was delayed in female rainbow trout on non-pigmented diets compared with those fed diets containing astaxanthin. In the present study, the triploid fish which were not monosexed had overall no sexual maturity resulting in more intense flesh pigmentation at each dietary level (Table 2).

Obvious differences in color parameters were measured for all groups of fish and dietary treatments, and the intensity of color increased with increasing time on the pigmented feed. The difference in yellowness may have been due to differences in the relative proportions of carotenoids in the flesh. Idoxanthin, a metabolite of astaxanthin, was found in greater proportions in mature fish compared to immature fish and might contribute to the increased yellowness of the flesh [17]. At maturity, astaxanthin is mobilized from the flesh to the skin (males) or gonads (females), leaving a greater proportion of other carotenoids. However, in the present study, the fish that had sexually matured had lower levels of yellowness than the immature fish. In addition, the triploid fish which do not mature sexually had the highest yellowness levels at the longest dietary pigment treatment so the increase may have been due to an increased supply of precursors to idoxanthin rather than a readjustment of the proportions of the carotenoids.

At each dietary treatment time period, the triploid fish had higher redness levels compared to the males or females demonstrating that some of the carotenoids were being diverted for use when sexually mature.

Consumption of a pigmented diet adversely affected body weight for all sexes of Arctic charr in this study. A decrease in feed intake may have been the cause, although the decrease may have been expected for the non-pigmented diet rather than the pigmented diets since, with the onset of sexual maturity, feed intake declines or ceases. This was not the case with the male and female fish on the non-pigmented diet in this study which had the highest body weights with the highest GSI. The fish density for the non-pigmented tank was $34.6 \mathrm{~kg} / \mathrm{m}^{3}$ and the density for the pigmented tank was $57.8 \mathrm{~kg} / \mathrm{m}^{3}$. Although the difference in density was not optimal from an experimental point of view, both were in the ideal range for Arctic charr and, therefore, should not have affected 
fish growth to a great extent [18].

As the intensity of the pigmentation increased, so did the variability of the pigment within the flesh, in particular for the male fish and the red pigmentation, and the females and the yellow pigmentation. Although the triploid fish had large increases in the color intensity from non-pigmented feed to six months of pigmented feed, there was no related increase in the variability of pigmentation, probably because they were not sexually mature. During sexual maturation, carotenoids from the flesh are mobilized and deposited in the skin of male fish and into the gonads of female fish [19], and this transfer is thought to be influenced by the steroid sex hormones 11-ketotestosterone and $17 \beta$-estradiol [20]. The male fish in the present study had increased skin pigmentation on the pigmented diets but a lower GSI compared to males on the non-pigmented diet. Reference [19] suggested that the deposition of carotenoids in the skin may be markedly influenced by dietary supply, the feeding of carotenoid-rich diets appearing to promote pigment deposition in the skin irrespective of the maturational status of the fish.

In the present study, the variability of red color $\left(\mathrm{a}^{*}\right)$ increased for male fish, and of yellow ( $b^{*}$ ) for female fish as the time on the pigmented feed increased, which is the opposite relationship that [21] found with rainbow trout.

Precocious maturation in Arctic charr is a problem in commercial farming operations because the maturation process is accompanied by a decrease in growth rate and a reduction in flesh quality [1]. In the present study, for the fish on the non-pigmented feed, over $10 \%$ of the body weight of the females and over $4 \%$ of the body weight of the males consisted of gonadal weight, demonstrating a diversion of dietary nutrients from the flesh to the gonads. The use of triploid fish, even non-sexed ones, seems warranted as both growth rate, nutrient partitioning and pigmentation was focused on the flesh. More studies are needed to determine if the presence of carotenoids in the diet can influence the onset of sexual maturity in Arctic charr.

\section{CONCLUSION}

Feeding a pigmented diet to Arctic charr delayed sexual maturity in male Arctic charr and to a certain extent in females, but also slightly reduced the rate of growth. With increasing time on the pigmented diet, color parameters of the flesh increased as well as the variability in color. Triploid fish had more intense color assessments for each dietary treatment than the diploid fish.

\section{ACKNOWLEDGEMENTS}

The authors gratefully acknowledge the Coastal Zones Research In- stitute, Shippagan, NB Canada.

\section{REFERENCES}

[1] Jobling, M., Tveiten, H. and Hatlen, B. (1998) Cultivation of Arctic char: An update. Aquaculture International, 6, 181-196. doi:10.1023/A:1009246509657

[2] Metusalach, J.A. and Brown, F.S. (1997) Effects of stocking density on color characteristics and deposition of carotenoids in cultured Arctic charr (Salvelinus alpinus). Food Chemistry, 59, 107-114. doi:10.1016/S0308-8146(96)00205-1

[3] Hardy, R.W., Torrissen, O.J. and Scott, T.M. (1990) Absorption and distribution of 14C-labelled canthaxanthin in rainbow trout (Oncorhynchus mykiss). Aquaculture, 87, 331-340. doi:10.1016/0044-8486(90)90070-4

[4] Chaisson, M.A., Pelletier, C.S. and Benfey, T.J. (2009) Triploidy and full-sib family effects on survival and growth in juvenile Arctic charr (Salvelinus alpinus). Aquaculture, 289, 244-252. doi:10.1016/j.aquaculture.2009.01.010

[5] Johnston, G. (2002) Arctic char aquaculture. Fishing news books. Blackwell Publishing, Oxford, 272.

[6] Benfey, T.J. (2001) Use of sterile triploid Atlantic salmon (Salmo salar) for aquaculture in New Brunswick, Canada. ICES Journal of Marine Science, 58, 525-529. doi:10.1006/jmsc.2000.1019

[7] Commission Internationale de l'Eclairage (CIE) (1986) Colorimetry. 2nd Edition, Publication CIE No. 15.2. Commission Internationale de l'Eclairage, Vienna.

[8] SAS (2004) SAS/STAT user's guide, version 9.1. SAS Institute Incorporated, Cary.

[9] Rajasingh, H., Våge, D.I., Pavey, S.A. and Omholt, S.W. (2007) Why are salmonids pink? Canadian Journal of Fisheries \& Aquatic Science, 64, 1614-1627. doi:10.1139/f07-119

[10] Christiansen, R. and Torrissen. O.J. (1997) Effect of dietary astaxanthin supplementation on fertilization and egg survival in Atlantic salmon (Salmo salar L.). Aquaculture, 153, 51-62. doi:10.1016/S0044-8486(97)00016-1

[11] Shahidi, F. and Metusalach, J.A. (1998) Carotenoid pigments in seafoods and aquaculture. Critical Reviews Food Science Nutrition, 38, 1-67. doi:10.1080/10408699891274165

[12] Evans, M.R. and Norris. K. (1996) The importance of carotenoids in signaling during aggressive interactions between male firemouth cichlids (Cichlasoma meeki). Behavior Ecology, 7, 1-6. doi:10.1093/beheco/7.1.1

[13] Foote, C.J., Brown, G.S. and Hawryshyn, C.W. (2004) Female color and male choice in sockeye salmon: Implications for the phenotypic convergence of anadromous and nonanadromous morphs. Animal Behavior, 67, 69-83. doi:10.1016/j.anbehav.2003.02.004

[14] Sylvia, G., Morrissey, M.T., Graham, T. and Garcia. S. (1995) Organoleptic qualities of farmed and wild salmon. Journal of Aquatic Food Production Technology, 4, 51-64. doi:10.1300/J030v04n01 04 
[15] Sylvia, G., Morrissey, M.T., Graham, T. and Garcia, S. (1996) Changing trends in seafood markets: The case of farmed and wild salmon. Journal of Food Production Marketing, 3, 49-63. doi:10.1300/J038v03n02_05

[16] Ahmadi, M.R., Bazyar, A.A., Safi, S., Ytrestöyl, T. and Bjerkeng, B. (2006) Effects ofietary astaxanthin supplementation on reproductive characteristics of rainbow trout (Oncorhynchus mykiss). Journal of Applied Ichthyology, 22, 388-394. doi:10.1111/j.1439-0426.2006.00770.x

[17] Hatlen, B., Jobling, M. and Bjerkeng, B. (1998) Relationships between carotenoid concentration and color of fillets of Arctic charr, Salvelinus alpinus (L.) fed astaxanthin. Aquaculture Research, 29, 191-202. doi:10.1111/j.1365-2109.1998.tb01124.x

[18] Jobling, M., Jørgensen, E.H., Arnesen, A.M. and Ringø. E. (1993) Feeding, growth and environmental requirements of Arctic charr: A review of aquaculture potential. Aquaculture International, 1, 20-46.

\section{doi:10.1007/BF00692662}

[19] Hatlen, B., Arnesen, A.M. and Jobling, M. (1996) Muscle carotenoid concentrations in sexually maturing and immature Arctic charr, Salvelinus alpinus (L.). Aquaculture Nutrition, 2, 207-212. doi:10.1111/j.1365-2095.1996.tb00061.x

[20] Bjerkeng, B., Johnsen, K., Mayer, I., Storebakken, T. and Olli, J.J. (1999) Influence of 11-ketotestosterone, $17 \beta$ estradiol and 3,5,3'-triiodo-thyronine on distribution and metabolism of carotenoids in Arctic charr, Salvelinus alpinus, L. Fish Physiology, 125B, 295-404.

[21] Nickell, D.C. and Bromage, N.R. (1998) The effect of timing and duration of feeding astaxanthin on the development and variation of fillet color and efficiency of pigmentation in rainbow trout (Oncorhynchus mykiss). Aquaculture, 169, 233-246. doi:10.1016/S0044-8486(98)00385-8 